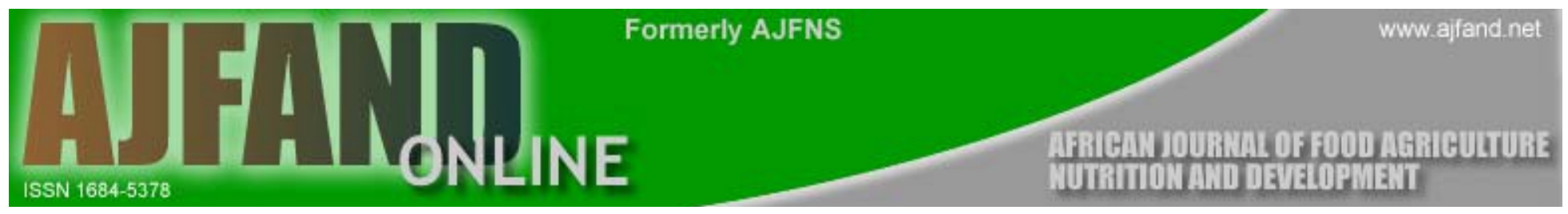

PEER REVIEWED ARTICLE No 6

\title{
NUTRITIVE VALUE OF THREE POTENTIAL COMPLEMENTARY FOODS BASED ON CEREALS AND LEGUMES
}

\author{
$\mathrm{S} \operatorname{Mariam}^{1 *}$
}

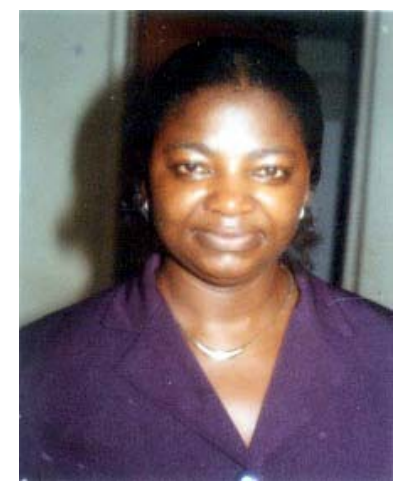

SOLOMON MARIAM

*Corresponding Author E-mail: danladis2003@yahoo.com

${ }^{1}$ Department of Biochemistry, Faculty of Medical of Sciences, University of Jos, P.M.B. 2084, Plateau State, Nigeria 


\begin{abstract}
The objectives of the study were to formulate composite blends (weaning foods) based on locally available cereals and legumes, to chemically evaluate their nutrient values, and compare with those of a proprietary formula and recommended daily allowance (RDA). The study is part of the effort to provide home-based complementary (weaning) foods that can be more cost effective to the low income families. Three composite blends were formulated based on protein basis of the food commodities used. Standard procedures of Association of Official Analytical Chemists (AOAC) were used to determine the proximate chemical composition. Technicon amino acid analyzer was used to detect and quantify neither amino acids using nor leucine as the internal standard, while atomic absorption spectrophotometer and ion chromatographic analyzer were used to determine the mineral element composition. The overall results indicated that crude protein, lipid, fibre, ash, moisture, energy and carbohydrate were either comparable or higher than values in the proprietary formula. The subject formulae would meet the RDA for protein, lipid, magnesium, manganese and fluoride based on an estimated daily intake of $65 \mathrm{~g}$ of weaning foods by a normal six months old infant in Jos, Nigeria. The subject diets would not meet the RDA for other nutrients based on the same estimation. It is therefore recommended that infants fed on these formulations be breastfed for at least two years, since the formulations are not intended to substitute breast milk, but to complement it. Frequent feeding on these foods is also recommended to increase daily nutrient intake. Inclusion of other nutrient-dense food commodities or appropriate micronutrients is necessary to raise the level of nutrients. The researchers believe that complementary foods formulated from locally available food commodities have great potential in providing nutritious foods that are practical, food-based approaches, aimed at combating the problem of malnutrition among infants and children in Nigeria in particular, and developing counties in general.
\end{abstract}

Key words: Complementary foods, Cereals, Legumes

\title{
INTRODUCTION
}

Scientifically, it has been proved that breast milk is the perfect food for the infant during the first six months of life. It contains all the nutrients and immunological factors an infant requires to maintain optimal health and growth. Furthermore, breast milk also protects infants against the two leading causes of infant mortality, upper respiratory infections and diarrhea [1]. However, at the age of six months and above when the child's birth weight is expected to have doubled, breast milk is no longer sufficient to meet the 
nutritional needs of the growing infant. Nutritious complementary foods are therefore introduced - also known as weaning foods - which typically covers the period from six to twenty four months of age in most developing countries [2].

On the other hand, nowadays, due to the reduced consumption of breast milk, important nutrients such as proteins, zinc, iron and B-vitamins are likely to be deficient in the contemporary diet of the affected infants [3]. If this development is not well handled during this crucial growth period, it can then lead to under-nutrition. For instance, the first Nigeria Nutrition Network of 2002 [4] identified poor feeding practices and/or shortfall in food intake, as the most important direct factors responsible for malnutrition and illness amongst children in Nigeria.

As in most other developing countries, the high cost of fortified nutritious proprietary complementary foods is always, if not prohibitive, beyond the reach of most Nigerian families. Such families often depend on inadequately processed traditional foods consisting mainly of un-supplemented cereal porridges made from maize, sorghum and millet. In view of this, appropriate processing and blending of locally available food commodities have been carried out and researched into by a number of researchers $[5,6$, 7]. Such blends have been found to improve nutrient density of the complementary food and improved nutrient intake, which resulted in the prevention of malnutrition problems. This approach would require knowledge about the nutritive values of a variety of local food commodities, indigenous to the affected communities.

A number of cereals and legumes that are readily available in Jos, Nigeria, have been found to have nutrient potentials that could complement one another if properly processed and blended [8,9]. Therefore, it is imperative that efforts to formulate composite blends and scientific studies are carried out to ascertain the nutritive adequacy of these locally available blends (cereal and legumes) for possible use as complementary foods, especially by the rural and poor urban mothers during weaning period.

This study is therefore part of exploratory work towards this goal. The primary aim of the study is to formulate some composite blends based on cereals like rice, Acha (local cereal - Digitaria exilis Stapf) and maize and legumes like groundnuts, benniseed (sesame seeds) and Soya beans and then chemically evaluate their respective nutritive values. It is also part of the study to compare the findings from the blend of such cereals with a proprietary formula commonly sold in Jos, Nigeria, as well as the RDA's to warrant recommendations in terms of nutritive values. 


\section{MATERIALS AND METHODS}

\section{Materials}

The food commodities - rice (Oryza sativa), maize (Zea mays L.), Acha grains (Digitaria exilis), soyabeans (Glycine max), groundnut (Arachis hypogea), Bambaranut (V-oardzie subterranae), benniseed (Sesumun indicum), carrot (Daccus carota), garden egg (Solanum incanum) and crayfish (Macrobrachium spp) - were used to formulate three composite blends (diets) used in this study. The foodstuffs were purchased from local markets in Jos, Nigeria. Also, for comparison purposes, a Nestle Cerelac (a product of Nestle Nigeria PLC), was purchased from Jos Central Market.

\section{Preparation of Food Commodities}

The dehulled cereals - paddy rice, yellow maize and Acha grains - were separately washed with tap water and air-dried for 12 hours. The Soya beans wre washed and soaked in tap water for 12 hours, washed by rubbing between the palms to remove testa, then washed again several times with more water. It was then boiled in water for 15 minutes, air-dried for 48 hours and then roasted in an oven at $70{ }^{\circ} \mathrm{C}$ for 30 minutes (soaking and roasting were intended to reduce the beany flavour). Similarly, the benniseed was also washed in water by rubbing between palms to remove testa, air-dried for 48 hours and roasted at $70{ }^{\circ} \mathrm{C}$ for 30 minutes. The groundnuts and bambaranuts were separately washed in tap water, air-dried for 12 hours and also roasted as stated above. Furthermore, carrot and ripened garden egg were separately washed with tap water, grated with a kitchen-grater and air-dried for 48 hours. Lastly, the processed food commodities were analyzed for their chemical proximate compositions (Appendix 1) and blends formulated based on the protein contents.

\section{Formulation of Composite Flours}

The composite flours of the three complementary foods were formulated as follows: Diet 1: Dehulled rice: Groundnut: Bambaranut: Carrot (RGB) (60:20:10:10 \% w/w) Diet 2: Acha grain: Benniseed: Crayfish: Garden egg (ABC) $(60: 25: 10: 5 \% \mathrm{w} / \mathrm{w})$

Diet 3: Yellow maize: Soya beans: Groundnut (MSG) (60:30:10 \% w/w)

The mixtures were separately milled in a $2 \mathrm{~L}$ mistral grinder into smooth homogenous powder and stored in airtight containers until the analyses time.

The Nestle Cerelac served as the control for assessing the nutrient levels of the composite blends against amounts of nutrients present in $65 \mathrm{~g}$ (dry weight estimate of the daily intake of local weaning food by a 6 months old infant) [9]. Then the blends were 
compared with RDA's to check whether the local diets met the nutrient recommendations $[10]$.

\section{Chemical Analyses}

Standard procedures of AOAC were used to determine the moisture content, crude fat, crude protein ( $\mathrm{N} \times$ 6.25), ash and Nitrogen free extract (NFE) [11]. Energy value was calculated using the Atwater's conversion factors [12]. Minerals were determined by a Zeeman Polarized Atomic Absorption Spectrophotometer, Hitachi Model 180-80, and Ion Chromatographic Analyzer ICA model IC 100.

The amino acid profile was determined with Technicon Amino Acid Analyzer (TSM-1) using Norleucine as internal standard [13]. Data were reported as the mean \pm SD for three determinations.

\section{RESULTS}

The proximate nutrient composition of the three local diets and the proprietary formula (Nestle Cerelac) are presented in Table 1. The results indicated that moisture, fibre, fat and energy values were higher in all the three local diets than in Nestle Cerelac. Protein was also higher in diets 2 and 3 than in Cerelac. Nitrogen free extract was higher in Cerelac than in diets 1 and 3, but comparable to diet 2. Ash contents were all comparable to values for Cerelac Product.

Having shown that most of the nutrient values were higher in local cereal and legume blends than in Cerelac product, again, a dry weighT of $65 \mathrm{~g}$ of the of local weaning foods of the composite diets were calculated and compared to recommended dietary allowances (RDA) for the same age groups [10]. The comparison result is presented in Table 2. The amounts of protein provided by $65 \mathrm{~g}$ of diets 2 and 3 (19.8 - 23.1 g) exceeded the RDA value $(13-14 \mathrm{~g})$, for infants up to 1 year of age. Diet 1 fell short of the RDA level. The higher protein content in diets 2 and 3 could be attributed to the positive contribution of crayfish and Soya beans to protein nutriture. Crude fat contents in $65 \mathrm{~g}$ of all the three local diets $(10.1-24.8 \mathrm{~g})$ met the RDA $(10-25 \mathrm{~g})$. However, the energy content of all the three diets was below that of RDA $(308-389 \mathrm{~K}$ cal $)$.

Table 3 shows the mineral contents of the local diets versus the Cerelac product. All mineral values of the three diets were lower than values in Cerelac product. When mineral amounts in $65 \mathrm{~g}$ of the diets were calculated and compared with RDA (Table 4), only $\mathrm{Mg}$ and $\mathrm{Mn}$ met the RDA in diets 2 and 3 and $\mathrm{F}^{-}$in all diets. Understandably, the higher mineral contents of Cerelac product could be attributed to fortification practices normally carried out on such products. 
The amino acid compositions of the three local diets are as presented in Table 5. The diets contain all the essential amino acids. The comparison of the essential amino acids to the FAO reference values [13], and percentage chemical scores are presented in Table 6 . This revealed that diets 2 and 3 contained higher scores of most essential amino acids than diet 1 . Only Phe and Trp met the FAO reference values in all the diets. Lys in diets 3 also met the FAO value. This therefore means that most of the essential amino acids fell short of the reference values.

\section{DISCUSSION}

Practically, the results of this study offer answers to some of the following questions:

- Can complementary foods formulated using locally available food commodities and processing methods meet the various recommendation from the National Research Council and the Food and Agricultural Organization/World Health Organization?

- Can such foods be used to substitute the more expensive proprietary formula, yet provide nutritious food for the infant?

Also from this study, it became clear that the local formulations compared favourably with the proprietary formula like Nestle Cerelac in terms of protein, fat, ash, fibre and energy contents, as well as RDA's for protein and fat. But the proprietary product has higher values of mineral content and amino acids than the subject diets. These short-falls could either be attributed to nutrient loss during processing, or poor micronutrient content of plant-based diets as reported by other researchers $[5,6,7]$.

Amino acid content of complementary foods is a particular relevant issue in infant feeding, where Protein-Energy-Malnutrition (PEM) has continued to pose challenges in the research area. This, according to other researchers, is due to poor feeding practices and low quality protein commonly associated with plant-based single diets $[6,7]$. All the essential amino acids were present in the three local diets, but quite a number of them did not meet the FAO reference values. This short-fall is a matter of concern as this will tend to limit the utilization of the amino acids in the metabolic processes of the body [11]. Diets composed of cereals/legumes mixed with some animal protein source $(10-20 \%)$, have been reported to be sufficiently high in amino acids to meet RNI's (Recommended Nutrient Intakes) [14]. For instance Diet 2, which contained about $10 \%$ crayfish, showed higher amino acid contents than the other two diets, which is the base agreement in line with above mentioned observation. 
From the analysis, Diet 2 and 3 in comparison with Diet 1 showed higher protein contents. This could be explained by the inclusion of crayfish and Soya beans in these two diets. Both food commodities have been recommended for infant feeding $[5,6,7,15]$ due to their positive contribution to protein nutrition levels.

The local diets were observed to be low in mineral contents relative to the proprietary formula and RDA's. The high content of anti-nutritional factors and poor bioavailability of minerals in plant-based foods $[6,7]$ as well as losses during processing play a vital role in micronutrient deficiency [4]. It is therefore obvious that even the low mineral contents in the local diets may not be available or utilized completely by the child. The researchers are of the view that the local formulations or diets would have to be further fortified with micronutrients to adequately complement breast milk.

The high moisture content of the local diets may affect the storage quality of the foods. High moisture content in foods has been shown to encourage microbial growth [7]. This is an important consideration in local feeding methods in Nigeria, because most mothers often prepare large quantities of dry infant foods and keep in containers, to avoid frequent processing, in order to have spare time and energy for other domestic activities. The researchers are of the view that food commodities which are intended to be used in the preparation of dry weaning foods should be properly dried, and then only small quantities are prepared at a time to avoid prolonged storage.

The fat content of the local diets were relatively higher than the proprietary formula, and also met the recommended dietary allowance. This could be attributed to the inclusion of oil-dense Soya beans in the local diets. This attribute tends to agree with the recommendations of FAO/WHO [14] that vegetable oils be included in foods meant for infants and children, which will not only increase the energy density, but also be a transport vehicle for fat soluble vitamins. The fat can also provide essential fatty acids like that of n-3 and n-6 Polyunsaturated Fatty Acids (PUFA's) needed to ensure proper neural development. Even though the fatty acid composition of the three local diets were not determined, research carried out by Fernandez and his colleagues [8] on the fatty acid composition of some Nigerian weaning foods, revealed that the foods were devoid of arachidonic and decosahexanoic acids, but high in linoleic and linolenic acids.

The Food and Agricultural Organization and the World Health Organization [14] have also recommended that foods fed to infants and children should be energy-dense ones. This, according to the recommendation, is necessary because low energy foods tend to limit total energy intake and the utilization of other nutrients as mentioned above. However, the total calculated energy values in $65 \mathrm{~g}$ of the three local diets fell below the RDA level. This suggests that infants may have to consume more quantities of the diets to meet their energy needs, which is often an impossible task considering the size of their 
stomach. Therefore, reformulation of the diets may be necessary to increase the carbohydrate content of the diets, which is particularly low in Diets 1 and 3.

\section{CONCLUSION}

This study revealed that ready-to-eat complementary food products formulated from locally available food commodities, can meet the macro nutritional needs of infants and children. However certain aspects like the digestibility and bio-availability of the macronutrients in these local diets need further investigations. On the other hand, the subject local weaning diets do not meet the recommended micronutrient (minerals) requirements of infants and children. Therefore, fortification with appropriate micronutrients or micronutrient-dense foodstuffs will be necessary.

When it comes to the question whether such local diets can be used to substitute the more expensive proprietary formula products, the researchers believe that complementary foods formulated from locally available food commodities, have great potential in this aspect. The results from this study suggest that proper reformulation and fortification of these local diets can provide nutritious foods that are suitable not only for weaning, but also as rehabilitation diet to malnourished children that can be more cost effective. This is believed to be a practical food-based approach aimed at combating the problem of malnutrition among infants and children in Nigeria and other developing countries. Further study is in progress to fortify the analyzed subject local diets, address the antinutritional factors, as well as the bioavailability of micronutrients in an effort to enhance this potential weaning food. 


\section{Table 1:}

Proximate Composition of the Composite Diets and Nestle Cerelac.

\begin{tabular}{lllll}
\hline Nutrient & Diet 1 & Diet 2 & Diet 3 & Nestle Cerelac* \\
\hline Moisture (\% wet weight) & $3.70 \pm 0.14$ & $4.90 \pm 0.04$ & $5.15 \pm 0.08$ & 2.50 \\
Ash (\% dry weight) & $2.05 \pm 0.07$ & $2.06 \pm 0.08$ & $2.60 \pm 0.14$ & 2.60 \\
Crude Protein (\% d. wt) & $13.31 \pm 0.22$ & $35.6 \pm 1.28$ & $30.4 \pm 0.86$ & 15.0 \\
Crude fat (\% d. wt) & $38.1 \pm 0.57$ & $15.6 \pm 0.21$ & $17.7 \pm 0.07$ & 9.00 \\
Crude fibre (\% d. wt.) & $9.07 \pm 0.26$ & $9.29 \pm 0.83$ & $10.8 \pm 0.35$ & 2.95 \\
NFE (\% d. wt.) & $47.3 \pm 1.80$ & $68.4 \pm 2.26$ & $45.8 \pm 2.40$ & 67.95 \\
Energy (K cal) & $598.5 \pm 14.24$ & $473.9 \pm 16.19$ & $523.5 \pm 17.29$ & 413.00 \\
\hline
\end{tabular}

Values are mean \pm SD for three determinations

* Values as indicated by the manufacturer

Table 2:

Estimated Amounts of Nutrient Provided by $65 \mathrm{~g}$ of the Local Composites compared with RDA.

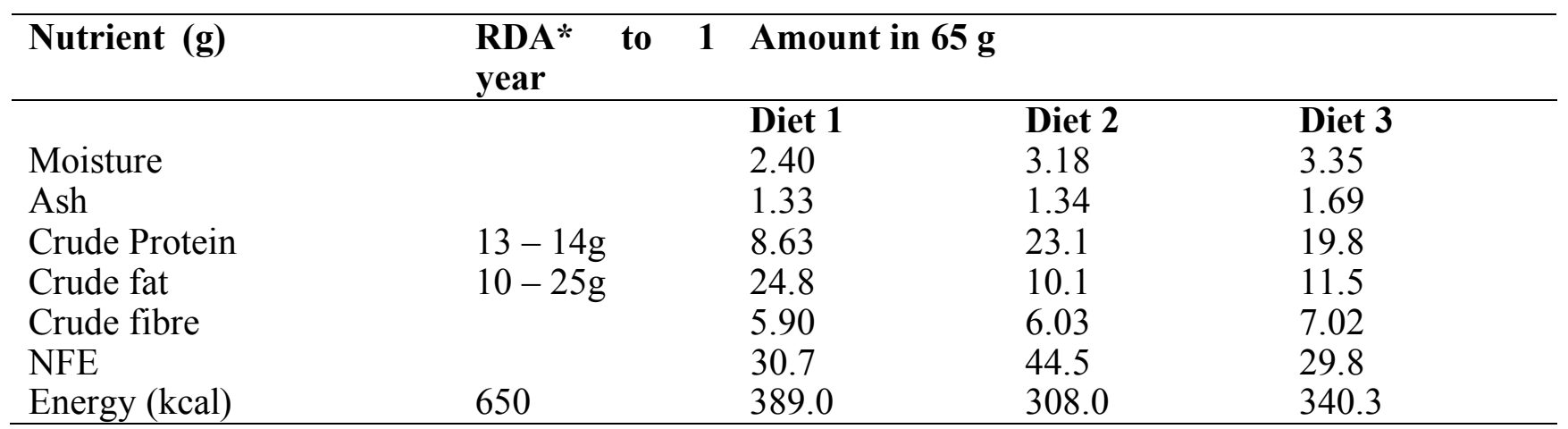

* Recommended dietary allowances adapted from Guthrie[11] 
Table 3:

Mineral Contents of the Local diets and Nestle Cerelac

\begin{tabular}{lllll}
\hline $\begin{array}{l}\text { Mineral } \\
(\mathbf{m g} / \mathbf{1 0 0} \mathbf{g})\end{array}$ & Diet 1 & Diet 2 & Diet 3 & Nestle Cerelac* \\
\hline $\mathrm{Na}$ & $21.1 \pm 0.08$ & $17.2 \pm 0.03$ & $11.1 \pm 0.02$ & 220.0 \\
$\mathrm{~K}$ & $129.7 \pm 33.83$ & $99.7 \pm 0.17$ & $128.8 \pm 15.17$ & 700.0 \\
$\mathrm{Mg}$ & $38.5 \pm 6.33$ & $110.9 \pm 20.50$ & $84.8 \pm 1.72$ & $\mathrm{NA}$ \\
$\mathrm{Ca}$ & $67.2 \pm 0.00$ & $185.6 \pm 31.67$ & $31.0 \pm 0.58$ & 420.0 \\
$\mathrm{Zn}$ & $1.01 \pm 0.01$ & $2.08 \pm 0.02$ & $1.75 \pm 0.01$ & 7.0 \\
$\mathrm{Fe}$ & $1.86 \pm 0.01$ & $2.08 \pm 0.56$ & $1.65 \pm 0.64$ & 10.0 \\
$\mathrm{Mn}$ & $0.37 \pm 0.02$ & $0.82 \pm 0.01$ & $0.71 \pm 0.03$ & $\mathrm{NA}$ \\
$\mathrm{F}^{-}$ & $0.73 \pm 0.31$ & $1.67 \pm 0.40$ & $0.40 \pm 0.13$ & $\mathrm{NA}$ \\
$\mathrm{Cl}^{-}$ & $23.4 \pm 1.22$ & $57.3 \pm 3.10$ & $4.17 \pm 0.44$ & $\mathrm{NA}$ \\
$\mathrm{PO}_{4}{ }^{3-}$ & $22.9 \pm 1.00$ & $12.1 \pm 0.55$ & $17.7 \pm 0.14$ & 315.0 \\
\hline
\end{tabular}

Values are means \pm SD for three determinations

* Values as indicated by manufacturer

NA - Information not available

Table 4:

RDA's Vs the amounts of mineral element $(\mathrm{mg})$ in $65 \mathrm{~g}$ of the local diets

\begin{tabular}{lllll}
\hline Mineral & *RDA up to 1 yr. & Diet 1 & Diet 2 & Diet 3 \\
\hline $\mathbf{N a}$ & 120 & 13.7 & 11.2 & 7.22 \\
$\mathbf{K}$ & 500 & 84.3 & 64.8 & 83.8 \\
$\mathbf{M g}$ & 40 & 25.0 & 72.1 & 55.1 \\
$\mathbf{C a}$ & 400 & 43.7 & 120.6 & 20.1 \\
$\mathbf{Z n}$ & 5.0 & 0.66 & 1.35 & 1.14 \\
$\mathbf{F e}$ & $\mathbf{3 n}$ & 1.21 & 1.35 & 1.07 \\
$\mathbf{M n}$ & $0.3-0.6$ & 0.24 & 0.53 & 0.46 \\
$\mathbf{F}^{-}$ & $0.1-0.5$ & 0.47 & 1.08 & 0.26 \\
$\mathbf{C l}^{-}$ & 180 & 15.2 & 37.2 & 2.71 \\
$\mathbf{P O}^{3-}$ & 300 & 14.2 & 7.86 & 11.5 \\
& & & & \\
\hline
\end{tabular}

* Recommended dietary allowance from Guthrie [11] 
Table 5:

Amino Acid Composition of the Local Composite diets (g/100 g Protein)

\begin{tabular}{lllll}
\hline Amino acid & FAO Ref. Value* & Diet $\mathbf{1}$ & Diet $\mathbf{2}$ & Diet 3 \\
\hline Lys. & 4.2 & 2.18 & 4.01 & 4.82 \\
Thr & 2.8 & 0.63 & 1.04 & 0.87 \\
Val & 4.2 & 2.67 & 3.70 & 2.88 \\
Cys & 2.0 & 1.00 & 1.70 & 1.65 \\
Met & 2.2 & 0.62 & 1.80 & 1.26 \\
Iso & 4.2 & 3.01 & 3.89 & 4.16 \\
Leu & 4.2 & 3.34 & 3.42 & 4.00 \\
Tyr & 2.8 & 2.50 & 2.94 & 2.80 \\
Phe & 2.8 & 4.00 & 4.47 & 4.10 \\
Trp & 1.4 & 3.32 & 3.98 & 3.11 \\
His & & 0.58 & 0.77 & 1.60 \\
Arg & & 2.51 & 3.00 & 3.45 \\
Asp & & 5.00 & 4.92 & 5.01 \\
Glu & & 7.60 & 6.63 & 8.81 \\
Pro & & 0.45 & 0.67 & 0.90 \\
Gly & & 1.12 & 1.44 & 2.00 \\
Ala & & 2.01 & 2.11 & 2.81 \\
Ser & & 2.23 & 2.40 & 2.45 \\
\hline
\end{tabular}

* Food and Agricultural Organization (FAO) [13] 
Table 6:

Percentage Chemical Scores of the Essential Amino Acids in the Local Composite diets

\begin{tabular}{llll}
\hline Amino Acid & Diet 1 & Diet 2 & Diet 3 \\
\hline Lys. & 51.9 & 97.2 & 118.8 \\
Thr & 22.5 & 37.1 & 31.1 \\
Val & 63.6 & 88.1 & 68.6 \\
Cys & 50.0 & 85.0 & 82.5 \\
Met & 28.2 & 81.8 & 57.3 \\
Iso & 71.7 & 92.1 & 99.1 \\
Leu & 79.5 & 81.4 & 95.2 \\
Tyr & 89.3 & 105.0 & 100.0 \\
Phe & 142.9 & 159.6 & 146.4 \\
Trp & 237.1 & 284.3 & 222.1 \\
\hline
\end{tabular}




\section{Appendix 1:}

Nutrient composition of the Foodstuffs used in the formulation of the Blends

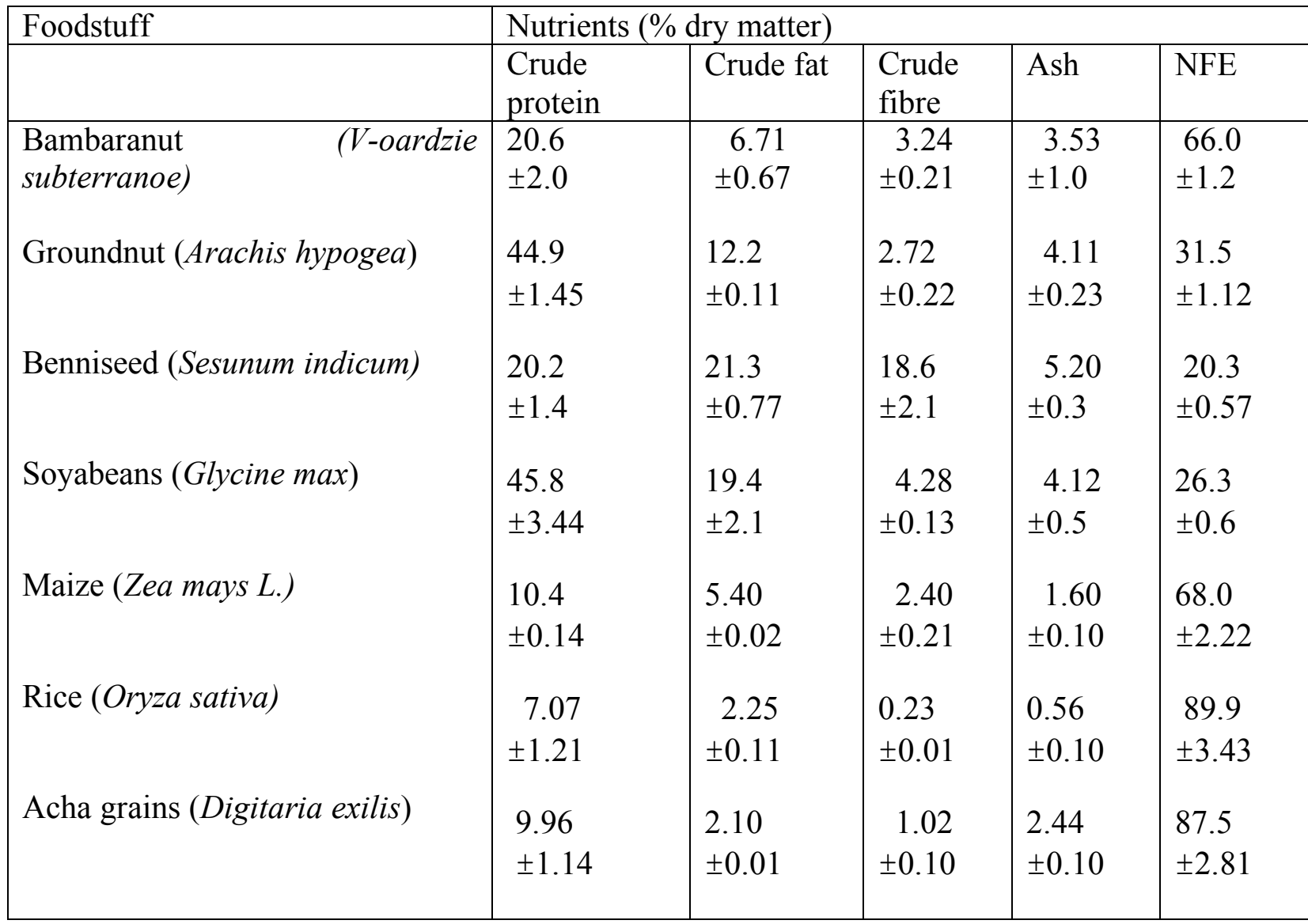

Values are means \pm SD of three analyses. 


\section{REFERENCES}

1. UNICEF Breastfeeding: Foundation for a healthy future. UNICEF, New York. 1999.

2. WHO/OMS Child and Adolescent Health and Development: Nutrition and Infant Feeding 2000.

3. La Leche League International (LLLI) Articles from LEAVEN: Introducing Complementary Foods. 2002.

4. Nigerian Nutrition Network (NNN) Communique and papers presented/distributed at the $1^{\text {st }}$ Annual NNN Meeting, Abeokuta, 12 - 13 December, 2000.

5. Nnam NM Evaluation of Complementary Foods based on Maize, Groundnut, Pawpaw and Mango flour Blends. Nig. J. Nutr. Sci 2002; 22\&23: 8 - 18 .

6. Badamosi EJ, Ibrahim LM and VJ Temple Nutritional Evaluation of a locally formulated Weaning food, JUTH-PAP. West Afr. J. Biol. Sci. 1995; 3: 85-93.

7. Temple VJ, Badamosi EJ, Ladeji $O$ and M Solomon Proximate Chemical Composition of three Locally Formulated Complementary Foods. West Afr. J. Biol. Sci. 1996; 5: $134-143$.

8. Fernandez DE, Vanderjagt DJ, Williams M, Huarg YS, Chuang Lut-te, Millson M, Andrew R, Pastuszyn A and RH Glew Fatty acids, amino acids, and trace mineral analyses of five weaning foods from Jos, Nigeria. Plants foods for Human Nutrition 2002; 57: 257-274.

9. Oguntona EB and IO Akinyele Nutrient Composition of Commonly eaten Foods in Nigeria - Raw, Processed and Prepared. Food Basket Foundation series. 1995.

10. National Research Council Recommended Dietary Allowance. $10^{\text {th }}$ ed. Washington DC: National Academy Press. 1989.

11 AOAC Official Methods of Analysis $-15^{\text {th }}$ ed. Association of Official Analytical Chemist., Washington D.C. 1990.

12. Spackman DH, Stein EH and S Moore Automatic Recording Apparatus for use in the Chromatography of Amino acids. Analytical Chemistry. 1958; 30: $1190-$ 1191. 
13. Guthrie AA Introductory Nutrition, $7^{\text {th }}$ ed. Times Mirror/ Mosby College Publisher. 1989: 485 - 576.

14. FAO/WHO Preparation and use of Food-Based Dietary Guidelines. Report of a Joint FAO/WHO Consultation. WHO Technical Report series 880. Geneva. 1998.

15. Owolabi AO, Mac-Inegite JO, Olowoniyan FO and HO Chindo A comparative Study of the Nutritional Status of Children in Villages in Northern Nigeria, using and not using Soya beans. Food Nutri. Bull. 1996; 17: 42 -48.

16. Honstra G, Al M van Houwelingen AC and $\mathbf{N}$ Foreman - van Drongelen. Essential Fatty Acids in Pregnancy and early Human Development.European J. Obs. \& Gyn.and Reproductive Biology. 1995; 61: 57 - 72. 